\title{
3D printed construction and implementation in Cyprus: Discussion and overview
}

\author{
Mohamed Elasad $^{*}$, Dinmukhamed Amirov ${ }^{1}$ \\ ${ }^{I}$ Civil Engineering Department, Faculty of Civil and Environmental Engineering, Near East University, Turkey
}

\section{A R T I C LE INFO}

\section{ARTICLE HISTORY:}

Received: 06 January 2020

Revised: 02 February 2020

Accepted: 22 April 2020

Published: 30 April 2020

\section{KEYWORDS:}

3D printing, additive

manufacturing, concrete, construction industry, fused

deposition modelling (FDM)

\author{
A B S T R A C T
}

The article describes the construction technology using three-dimensional printing. The use of $3 D$ printing allows the engineers to implement architectural projects of any complexity, to reduce the amount of industrial waste, the deficit of housing, and material, energy and labour costs for construction. The article discusses the leading technologies that are used to print buildings and structures, their distinguishing features, methods of their application with examples of finished work. The issue of materials used for the manufacture of building mixtures and the present situation of $3 D$ printing on the global market was identified in this investigation. All the positive and negative aspects of the $3 D$ printing construction are listed. The construction companies, equipment manufacturers and research centres, which are the main participants in the market, are reviewed. The primary purposes of the study are the determination of the possibility of implementation of additive technologies in Cyprus and the promotion of innovative construction methods.

\section{INTRODUCTION}

Since the beginning of the $20^{\text {th }}$ century, automation of production has been growing in almost all areas. The implementation of automation in the construction industry was hindered by a constructive approach, a significantly smaller amount of finished products compared to other industries, as well as the economic unattractiveness of expensive equipment and limitations in materials that lend themselves to automated production (Anjuma, 2017; Poullain, 2018). The construction industry today faces such severe problems as low labour productivity, high risk of injury at construction sites, the complexity of monitoring construction processes, and the lack of skilled workers. The construction industry is one of the largest consumers of nonrenewable resources and natural materials around the world.

A significant obstacle to the widespread introduction of additive technologies is the lack of a base of national standards for additive manufacturing, in particular, on the general and special qualifications of materials, structures, technologies, equipment, quality control, and the procedure for using additive manufacturing products (Bos, 2016;
Marchment, 2019). The use of additive technologies in construction requires the development and study of new materials used in 3D printing. However, many developers are faced with the problem of outsourcing materials.

\subsection{PRINTING TECHNOLOGY AND MATERIALS}

\subsection{Technology}

Fused Deposition Modelling (FDM) is the technology used in 3D printing in which the printer extrudes building material out of the nozzle in the form of a layer and stacks the layers according to the programmed 3D model, growing the walls of the building. Currently, many programs have been developed to create a 3D model. Most of these programs are freely available (Malysheva, 2013).

After creating a building model in the software package, information is transmitted by wire from a computer to a $3 \mathrm{D}$ 
printer in G-code. Note that a G-code is a set of coordinate points along which a $3 \mathrm{D}$ printer draws material, as a result of which a physical object appears. To manage the printer functionalities, third-party provided programs such as Cura, Polygon, Repetier-Host exist, but in some cases, the printer control program is provided by its manufacturer.

\subsection{Materials}

Concrete for building printing should be suitable for extrusion through a print head that extrudes yarns. The yarns of the previous layer should bind to the yarns of the next layer to form a monolithic composition. In this case, the concrete should be laid in regular even layers without spreading, and be rigid enough to support the following layers. This stiffness should be combined with a reduced setting time - the applied layers must remain chemically active in order to form a single structure at the point of contact. A reduction in setting speed is also necessary for the smooth operation of the equipment - so it will not be clogged with hardening concrete (Akhtyamova, 2018; Vatin, 2017).

For printing use fine-grained mixtures, which differ from traditional concrete, each company develops its recipe, which corresponds to the device of the printer and its nozzle, as well as the manufactured product. The most critical concrete parameters for a 3D printer are strength, curing speed, ductility. The necessary strength of concrete is selected by adjusting the composition of the mixture - the amount of cement and the quality of aggregates, as well as the addition of superplasticisers. Plasticising agents significantly increase the mobility of the mixture and reduce the water-cement ratio, which significantly increases the strength of concrete (Akhtyamova, 2018; Vatin, 2017).

Back in 2012, Loughborough University described in detail the work on selecting the optimal concrete mix. In this example, it can trace the definition of the main parameters for a fresh cement mixture. The developers aimed to choose the composition of concrete with a compressive strength of $100 \mathrm{MPa}$ and bending strength of $12 \mathrm{MPa}$ for 28 days. Printing was carried out on a portal printer with a nozzle opening of $9 \mathrm{~mm}$. Building mixtures were evaluated according to four parameters: extrudability, workability, buildability and open time. Good extrudability was achieved in the same way as when creating self-compacting and sprayed concrete. Under this condition, the correct selfsealing threads with an oval cross-section were obtained. It is more challenging to choose a composition suitable for assembly - it was achieved by regulating workability and proportions of the mixture, as well as by changing workability over time (action time). Here, the developers faced a dilemma - the ability to assemble required a long time, otherwise the mixture quickly loses workability, which reduces the extrusion rate and can lead to equipment blocking. On the other hand, high duration of action can lead to deformation of the threads (Akhtyamova, 2018).

Under $9 \mathrm{~mm}$ the width of the nozzle was selected sand with a particle size of $2 \mathrm{~mm}$. The cement of the first group, fly ash and micro-silica served as a binder. To reduce the water-cement ratio, increase workability and increase strength, a polycarboxylate superplasticiser was used. The retardation of the setting was carried out using formaldehyde nitro trimethyl phosphonic and citric acids these additives are necessary to increase the duration of the action and to facilitate a constant flow during printing. The mixture also used a hardening accelerator in the form of a combination of sulphuric acid, aluminium salt and diethanolamine. To reduce shrinkage and prevent deformation in the plastic state, polypropylene fibre was added to the mixture (length $12 \mathrm{~mm}$, diameter $0.18 \mathrm{~mm}$ ) (Akhtyamova, 2018; Vatin, 2017).

In total, five compositions were tested with different ratios of the main components - sand, cement, fly ash, silica fume and water. According to the four criteria identified, the best parameters were for a mixture with $\mathrm{W} / \mathrm{C}=0.26$ and a binder composition of $70 \%$ cement, $20 \%$ fly ash and $10 \%$ silica fume, $1.2 \mathrm{~kg} / \mathrm{m}^{3}$ of micropropylene fibres, (W= water, $\mathrm{C}=$ cement). The ratio of binding components to sand is 40:60. $1 \%$ superplasticiser, $0.5 \%$ moderator were added to the mixture - with their help, action time of 100 minutes was achieved. The compressive strength on day 28 was $110 \mathrm{MPa}$ (Akhtyamova, 2018).

Prior to this study, in 2011, Loughborough University described a composition based on cement and gypsum, but due to a large number of voids, the strength was lower - 80$88 \mathrm{MPa}$. There is also mention that Winsun used highquality cement and glass fibres for printing in 2014 (Akhtyamova, 2018; Vatin, 2017).

In 2015, Contour Crafting tested its construction printer with a concrete mix consisting of cement (CEM II. A 42.5 $\mathrm{R}$ ), the sand of various sizes, fly ash, micro-silica and superplasticiser. The strength after five days of exposure was relatively low - $45 \mathrm{MPa}$ (Akhtyamova, 2018).

Liang and Liang proposed using mixtures with a high content of construction waste and recycled materials - this reduces the cost of housing and allows to build homes in China quickly. However, the strength of such structures remains in question. There are also works where regular concrete is declared as raw material. For example, HuaShang Tengda used C30 concrete for the construction of a two-story building, which could be a potential raw material for budget constructions. Also in Yaroslavl, "SPETSAVIA" produces printers that print with standard M-300 sand concrete. Printing is done in layers of $10 \mathrm{~mm}$ high and 30 to $50 \mathrm{~mm}$ wide (Akhtyamova, 2018). 


\section{PROCESS OF 3D PRINTED CONSTRUCTION}

There are three general steps in producing the finished 3D concrete structure, and they are;

1. Preparing a 3D model: First, in a 3D modelling framework, a model is built. It is then exported in a standard format of 3D data exchange such as STL. Then, the stored data is analysed so that the model can be broken down into slices; this results in a sequence of $2 \mathrm{D}$ contour lines that are further translated to produce control commands for the position of the print head (Sakin, 2017). Luckily, the software and hardware standard of 3D computer graphics allows these digital models to be created without much trouble using many commercial and open-source software packages (Hager, 2016).

2. The second step is the preparation of material (concrete): This is the stage that involves labour force. The concrete is mixed and placed into the $3 \mathrm{D}$ printer's container; it is then pumped through the nozzle system that extrudes the concrete in layers according to the 3D model designed (Bos, 2016). As mentioned in the materials section; there are essential characteristics of 3D printed concrete which vary depending on the design of the mix, the distribution system, and the deposition device. These characteristics are; (Pacewicz, 2018).

- Pumpability: The quick and secure transfer of content through the delivery system.

- Printability: The capability and durability of depositing material via a depositing tool.

- Buildability: Resistance to deformation under the pressure of a settled wet material.

- Open time: The duration in which the properties listed above are compatible with reasonable tolerances.

3. Lastly, the printing step: The printing process includes a control system, which can usually be separated into two categories: gantry systems and robotic arm systems.

The gantry system drives a manipulator mounted onto an overhead to locate the print nozzle in XYZ coordinates while robotic arms provide additional freedom to the nozzle (Bos, 2016; Wikipedia, 2019). As mentioned in the technology section, there are universal programs for controlling the printer, such as Cura, Polygon, and RepetierHost.

\section{EXAMPLES OF EXISTING 3D PRINTED PROJECTS WORLDWIDE}

\subsection{New story $\&$ icon}

New Story, a non-profit and Icon a construction technologies company, partnered on a project that set out to end global homelessness and to give shelter to people and families affected by natural disasters. They unveiled the first permitted 3D printed house on the $15^{\text {th }}$ of March, 2014, in Austin, Texas. It measures 800 square feet, and it took less than 24 hours to build with a cost of $\$ 4000$ (PR, 2018).

\subsection{DFAB HOUSE}

The DFAB HOUSE is a structure made from predominantly digital technologies. The 200 square meters, three-story structure lays on top of the NEST platform in Dübendorf, Switzerland. It was launched in February of 2019 (Empa, n. d.).

\subsection{The BOD office hotel}

BOD stands for "Building on Demand", and it is the first 3D printed building in Europe. It is located in Denmark. With an area of 50 square meters. Designed by the company COBOD, it is designed to illustrate the economic and architectural advantages of 3D printing buildings. Thus, the building does not have any straight walls (COBOD, n. d.).

\subsection{2-story 3D printed villa}

Created by the Chinese company HuaShang Tengda, this 2-story villa was constructed entirely on-site in only 45 days. The villa measures at 400 square meters, with walls of the villa being $250 \mathrm{~mm}$ thick and made with 20 tons of C30grade concrete. It was unveiled in June of 2016 and is located in Tongzhou district of Beijing, China (Augur, 2016).

\subsection{Apis Cor 3D printed house}

Located in Stupino, Russia, this 3D house was created by Apis Cor in December of 2016. With the main components manufactured entirely on-site with concrete material, the company has been able to cut transport and assembly costs. Apis Cor was able to create heating insulation on-site using a mix of solid elements and liquid polyurethane. The project took only 24 hours to complete and a total cost of $\$ 10,000$. The house measures 38 square meters (Jamie, 2018).

\subsection{The world's first 3D printed office building}

Unveiled on the $23^{\text {rd }}$ of March of 2016 in Dubai, UAE, the so-called "Office of the future" was designed by Gensler and produced by the Chinese construction company Winsun. It is intended to be the HQ for the Dubai Futures Foundation. It was constructed in 17 days in total. The building measures at 240 square meters, with a cost of $\$ 140,000$ (not including finishing costs) (Government media office, 2016). 


\subsection{D printed castle}

Andrey Rudenko created this project in his backyard. The 3D printing system is capable of printing concrete layers at just $10 \mathrm{~mm}$ by $30 \mathrm{~mm}$. This allows for exceptional precision and detail in each layer, particularly when it comes to concrete $3 \mathrm{D}$ printing. The castle measured at $3 \times 5$ meters and was completed in 2014 in Minnesota, USA (Rudenko, n. d.).

\subsection{The world's first 3D printed apartment building}

This project was created by the Chinese construction company Winsun in the Province Jiangsu, China, in 2014. The 6-story apartment building measures at 1,100 square meters. The walls and other structural elements were manufactured off-site in 3D and subsequently transferred for assembling. The company's patented 3D printer ink made of construction waste, and a hardening agent was used in the construction of the walls. The material has the characteristics of high strength and insulation, allowing the structure to be resistant to earthquakes (Winsun, n. d.).

\section{ADVANTAGES AND DISADVANTAGES OF 3D PRINTED CONSTRUCTION}

The main differences between 3D printing and traditional methods in construction are in the time it takes to finish a project, the total cost of the project, the labour force needed to complete the project, and the structural complexity that can be achieved. Despite the many benefits of technology, it is relatively new; thus, it has many disadvantages that have to be worked on in the future to perfect the technology. These will be mentioned below in the list of advantages and disadvantages.

\subsection{D technology benefit}

- Low labour costs: For the construction of printed objects, $50-80 \%$ fewer labour costs is needed. The participation of people is only necessary for servicing machines, conducting communications, assembling structures.

- Fast construction: During construction immediately on the foundation, the erection of walls can occur in a matter of days. The most time-consuming part is the construction of the roof, communications and interior decoration.

- Minimum waste: Traditional construction leaves behind tons of waste per year. These are mainly scraps of materials, pieces of concrete, scaffolding and contaminated formwork. 3D printing of buildings leaves much less debris and can use recycled waste as components of the concrete mix.
- Low price: The first printed Russian house cost only 560 thousand rubbles. This price includes decoration and communications.

- Architectural freedom: Almost any geometric shapes are available to developers, and building objects with a more sophisticated architecture do not take much longer than traditional houses.

- An example is the Total Kustom children's castle and a two-story mansion in China.

- Construction on site: Traditional construction requires tremendous labour when transporting concrete slabs. The weight of some of them reaches 5 tons! 3D printing of buildings immediately on the foundation solves this problem (Akhtyamova, 2018).

\subsection{Technology disadvantages}

- Inconsistency of development: manufacturers do not share information, which slows down the development of the industry. Every company that begins to work in this area practically researches scratch (Akhtyamova, 2018).

- The high price of the printer: It can reach 2.5 million dollars. For small organisations and temporary projects, this cost can be unbearable. Fortunately, some manufacturers lease equipment.

- Fittings, wiring and sewerage still need to be done manually. We assume that in the future, these processes will also be robotic - Contour Crafting is already actively engaged in such developments. They claim that they can build an entire house in just 24 hours.

- Rough surface on most objects: At the walls, erected by a layered method, a ribbed surface. To make them even, finishing is necessary - mechanical alignment, plastering or the use of facing materials.

- Sensitivity to environmental conditions: Printing should not be carried out at low temperatures and adverse weather conditions. In cold weather, a tent is usually erected around the construction site - this requires separate costs. This problem can be partially solved by developing a concrete mix with frostresistant additives, which will retain its characteristics at low temperatures (Akhtyamova, 2018).

- The printer cannot replace a manufacturing enterprise, as it is not designed for an array of materials.

- Increased risks: any error in the digital model can be transmitted to the construction site.

- Small enterprises are not competitive with this type of production, which subsequently leads to their displacement from the market.

- At the moment, a limited amount of materials is used; however, scientists from around the world are developing in this direction (Airapetyan, 2018).

We tried to list all the shortcomings of the technology, with which we still have to work in the future. To fully adopt 
this technology in construction, a lot of research and discoveries will still be required. Although scientific research in this area already has great potential in its implementation in reality. Nonetheless, large world organisations and large corporations that have a stake in this are now participating in the research and development of new building technologies - 3D printing of buildings can bring the real estate and related industries to a radically new level.

\section{IMPLEMENTATION IN CYPRUS}

A significant obstacle to the widespread adoption of additive technologies in Northern Cyprus is the lack of a base of national standards for additive production, in particular, on the general and special qualifications of materials, structures, technologies, equipment, quality control, quality control and the procedure for using additive manufacturing products (Vatin, 2017).

The use of additive technologies in construction requires the development and study of new materials used in 3D printing. However, many developers are faced with the problem of selecting materials. The fundamental relationships of industry concept 4.0 (construction material - technology) are not yet integrated into the construction industry. This article discusses the world experience in the study and application of building materials based on concrete mixtures used for building additive technologies, as well as the properties of these mixtures and individual components. The article also provides an overview of existing building technologies of threedimensional printing, researched and implemented around the world.

The development of 3D printing can be seen on an infographic, created in 2015 by Landenberg. The diagram represents a map where developments are related to location, time, and construction material. As it is shown on the chart, in 2012, a turning point occurs. The number of 3D printing objects being developed is growing many times, turning the linear development of events into exponential (Akhtyamova, 2018).

According to Markets and Markets forecasts, the 3D printing market will continue to grow worldwide. Threedimensional concrete printing can reduce the amount of construction waste by $30-60 \%$, can reduce production time by $50-70 \%$ and reduce labour costs by $50-80 \%$. The agency estimates that the global market for 3D printing with concrete will grow to $\$ 56.4$ million by 2021 (Akhtyamova, 2018).

\section{CONCLUSION}

Additive technologies are used in various spheres of human life. Widespread is only a matter of time. Yes, there are many gaps in it, but they can be corrected if you invest in research and work together. Moreover, from the advantages of a $3 \mathrm{D}$ printer in construction, the economic and environmental spheres of man will only improve. For example, in countries with a large percentage of the poor and places after natural disasters, you can cheaply and quickly rebuild homes for residents.

We look forward to the further development of technology. The next step will be the use of robots that can do all the work: building walls, installing a roof, managing communications, furnishing a house with stairs and windows, exterior and interior decoration.

Nevertheless, there is still much work ahead. It is necessary to develop concrete mixtures with compositions for specific environmental conditions. Minimise construction waste and its further use.

Therefore, it is safe to say that with the help of $3 \mathrm{D}$ printing, it is possible to build quickly and inexpensively reliable buildings from high-quality materials with concern for nature and human health relative to traditional construction.

\section{REFERENCES}

[1] Akhtyamova, E. R. \& Kropachev, R. V. (2018). Prospects for application of $3 \mathrm{D}$ printers in mass construction, Apriori.

[2] Bong, S., Nematollahi, B., Nazari, A., Xia, M. \& Sanjayan, J. (2019). Method of Optimisation for Ambient Temperature Cured Sustainable Geopolymers for 3D Printing Construction Applications. Materials, 12(6), 902. https://doi.org/10.3390/ma12060902

[3] Bos, F., Wolfs, R., Ahmed, Z. \& Salet, T. (2016). Additive manufacturing of concrete in construction: potentials and challenges of 3D concrete printing. Virtual and Physical Prototyping, 11(3), 209-225. https://doi.org/10.1080/17452759.2016.1209867

[4] Guo, H., Lv, R. \& Bai, S. (2019). Recent advances on $3 \mathrm{D}$ printing graphene-based composites. Nano Materials Science, 1(2), 101-115. https://doi.org/10.1016/j.nanoms.2019.03.003

[5] Hager, I., Golonka, A. \& Putanowicz, R. (2016). 3D Printing of Buildings and Building Components as the Future of Sustainable Construction? Procedia Engineering, 151, 292-299. https://doi.org/10.1016/j.proeng.2016.07.357

[6] Ji, G., Ding, T., Xiao, J., Du, S., Li, J. \& Duan, Z. (2019). A 3D Printed Ready-Mixed Concrete Power 
Distribution Substation: Materials and Construction Technology. Materials, 12(9), 1540. https://doi.org/10.3390/ma12091540

[7] Malysheva, V. L. \& Krasimirov, S. S. (2013), 3D printer opportunities in construction, Actual problems of humanitarian and natural sciences, 352-354.

[8] Marchment, T., Sanjayan, J. \& Xia, M. (2019). Method of enhancing interlayer bond strength in construction scale 3D printing with mortar by effective bond area amplification. Materials \& Design, 169, 107684. https://doi.org/10.1016/j.matdes.2019.107684

[9] Ogura, H., Nerella V. \& Mechtcherine, V. (2018). Developing and Testing of Strain-Hardening CementBased Composites (SHCC) in the Context of 3DPrinting. Materials, 11(8), 1375. https://doi.org/10.3390/ma11081375

[10] Papachristoforou, M., Mitsopoulos, V. \& Stefanidou, M. (2018). Evaluation of workability parameters in 3D printing concrete. Procedia Structural Integrity, 10, 155-162. https://doi.org/10.1016/j.prostr.2018.09.023

[11] Shatornaya, A. M., Chislova, M. M., Drozdetskaya, M. A. \& Ptuhina, I. S. (2017). Efficiency of 3D printers in Civil Engineering, Construction of Unique Buildings and Structures, 60(9). 22-30. https://doi.org/10.18720/CUBS.60.2

[12] Sobotka, A. \& Pacewicz, K. (2016). Building Site Organization with 3D Technology in Use. Procedia Engineering, 161(2016), 407-413. https://doi.org/10.1016/j.proeng.2016.08.582

[13] Vatin, N., Chumadova, L., Goncharov, I., Zykova, V., Karpenya, A., Kim, A. \& Finashenkov, E. (2017). 3D printing in construction, Construction of Unique Buildings and Structures, 27-46. https://doi.org/10.18720/CUBS.52.3

[14] Yang, H., Zhu, K. \& Zhang, M. (2019). Analysis and Building of Trading Platform of Construction 3D Printing Technology and Products. Mathematical Problems in Engineering, 2019, 1-11. https://doi.org/10.1155/2019/9507192

[15] Zhu, B., Pan, J., Nematollahi, B., Zhou, Z., Zhang, Y. \& Sanjayan, J. (2019). Development of 3D printable engineered cementitious composites with ultra-high tensile ductility for digital construction, Materials \& Design, 181(2019). https://doi.org/10.1016/j.matdes.2019.108088

[16] Anjuma, T., Dongrea, P., Misbaha, F. \& Nanyama, N. (2017). Purview of 3DP in the Indian Built Environment Sector, Creative Construction Conference 2017, 196(2017) 228 - 235. https://doi:10.1016/j.proeng.2017.07.194

[17] El Sakka, F. \& Hamzeh, F. (2017). 3D concrete printing in the service of lean construction, 25th Annual Conference of the International Group for Lean
Construction - Heraklion, Greece - 2017(2) 781-788. https://doi.org/10.24928/2017/0246

[18] Inozemtcev, A., Korolev, E. \& Qui, D. T. (2018). Study of mineral additives for cement materials for 3Dprinting in construction, IOP Conf. Series: Materials Science and Engineering 365, 032009. https://doi:10.1088/1757-899X/365/3/032009

[19] Jianchao, Z., Zhang, T., Faried, M. \& Wengang, C. (2017). 3D printing cement based ink, and it's application within the construction industry. MATEC Web of Conferences, 120, 2003. https://doi.org/10.1051/matecconf/201712002003

[20] Lin, J. C., Wu, X., Yang, W., Zhao, R. X. \& Qiao, L. G. (2018). Application of P.O and R-SAC mortar for 3D printing in construction, IOP Conf. Series: Materials Science and Engineering, 292(2018) 012070. https://doi:10.1088/1757-899X/292/1/012070

[21] Lushnikov, N. D., Alterman, A. D. \& Parfenova, A. S. (2018). Printing opportunities 3D printer, XXXIII International Scientific and Practical Conference | ICSN "Science and Education" 2(2018), 878-882.

[22] Mikolajczyk, T., Malinowski, T., Moldovan, L., Fuwen, H., Paczkowskia, T. \& Ciobanud, I. (2019). CAD CAM System for Manufacturing Innovative Hybrid Design Using 3D Printing, The 12th International Conference Interdisciplinarity in Engineering, 32(2019) 22-28. https://doi.org/10.1016/J.PROMFG.2019.02.178

[23] Mohd, A. L, Omar, S.A, Yehia, Z, Al-Ojaili, S, Hashim, A. \& Orhan, O. (2018). Cost viability of 3D printed house in the UK, IOP Conference Series: Materials Science and Engineering, 319(1). https://doi:10.1088/1757-899X/319/1/012061

[24] Pacewicz, K., Sobotka, A. \& Gołek, T. (2018). Characteristic of materials for the 3D printed building constructions by additive printing, MATEC Web of Conferences 222(2018), 01013. https://doi.org/10.1051/matecconf/201822201013

[25] Poullain, P., Paquet, E., Garnier, S. \& Furet, B. (2018). On-site deployment of 3D printing for the building construction - The case of YhnovaTM, MATEC Web of Conferences, 163(2018), 01001. https://doi.org/10.1051/matecconf/201816301001

[26] Sakin, M. \& Kiroglu, Y. C. (2017). 3D Printing of Buildings: Construction of the Sustainable Houses of the Future by BIM, Energy Procedia 134(2017) 702711. https://doi.org/10.1016/j.egypro.2017.09.562

[27] Sharanova, A. V., Panfilova, A. D., Plahtiy, A. A. \& Dmitrieva, M. A. (2018). Investigation of the viscosity of construction mixtures applied for 3D printing, IOP Conference Series: Materials Science and Engineering, $525(1)$. https://doi.org/10.1088/1757-899X/525/1/012055 
[28] Tan, K. (2018). The Framework of Combining Artificial Intelligence and Construction 3D Printing in Civil Engineering, MATEC Web of Conferences 206(01008).

https://doi.org/10.1051/matecconf/201820601008

[29] Augur, H. (2016). This On-Site 3D Printed House Took Only 45 Days. All3dp. https://all3dp.com/21776-2/ Retrieved 28 December 2019

[30] COBOL. (n.d.). Europe's first 3D printed building. Cobod. https://cobod.com/the-bod/

[31] Empa. (n.d.). DFAB HOUSE is officially open! DFAHOUSE. https://dfabhouse.ch/2019/02/27/dfabhouse-is-officially-open/

[32] Government of Dubai media office. (2016). Mohammed inaugurates world's first 3D Printed Office Building. $\quad$ https://mediaoffice.ae/en/mediacenter/news/23/5/2016/3d-printed-officebuilding.aspx Retrieved 28 December 2019

[33] ICON PR. (2018). New Story and ICON Unveil the First Permitted 3D-Printed Home. Iconbuild. https://www.iconbuild.com/updates/this-house-canbe-3d-printed-for-cheap Retrieved 28 December 2019

[34] Jamie D. (2018). 3D Startup: Apis Cor, Creators of the $3 D$ Printed House. 3Dnatives. https://www.3dnatives.com/en/apis-cor-3d-printedhouse-060320184/ Retrieved 28 December 2019

[35] Rudenko. A. (n.d.). 3D Printed Concrete Castle is Complete. Totalkustom. http://www.totalkustom.com/3d-castlecompleted.html Retrieved 28 December 2019

[36] Winsun. (n.d.). Chinese 3D printing architecture is famous in the world and participates in US super highspeed rail. Winsun3d.

http://www.winsun3d.com/En/News/news_inner/id/25 4 Retrieved 28 December 2019

[37] Wikipedia. (2019). Construction 3D printing. Wikipedia.

https://en.wikipedia.org/wiki/Construction_3D_printin g\#Design Retrieved 29 December 2019 